\title{
INTEGRATING ECOSYSTEM SERVICES INTO INDUSTRIAL LOCATION STUDIES: A FUZZY HIERARCHIC APPROACH
}

\begin{abstract}
We propose an approach based on Fuzzy Logic and structured Hierarchy Analysis for integrating ecosystem services into industrial location studies. For such, we adopt the concept of ecosystem services (ES) defined by the Millennium Ecosystem Assessment (MEA). Although studies considering ES in land use decisions exist, few are those, which exploit them as industrial location factors. In this role, ES may be understood as benefits industries obtain from regional ecosystems candidates for location. However, use of ES by industries may cause impacts (costs) of diverse nature and intensity on ecosystems. Of complex valuation in quantitative absolute terms, these benefits and costs may be estimated in relative terms, respectively, by the relative dependence of industries on ES availability in the regions, and by the relative impacts of industries on regional ecosystems, all according to the perception of experts. The framework proposed here utilizes this relative evaluation to integrate ES into locational studies.
\end{abstract}

Keywords: Industrial Location; Ecosystems Services; Fuzzy Logic; AHP.

\section{Introduction}

Implantation of industries in specific sites may have a significant impact on ecosystems, but also depends on the services provided by them. Traditional analysis of industrial location already includes concerns about interactions with natural ecosystems, but still clings to the understanding of separation of production systems and the environment. Here, we focus on ecosystem services (ES) as locational factors in plant site selection. The valuation of benefits and costs of ES, which serves as basis for comparisons between locations, is addressed with the COPPE-Cosenza Hierarchy Model, Fuzzy Logic and the Analytic Hierarchy Process (AHP).

\section{Literature Review}

We resort to four main sources. Sustainability, which deals with ecosystems services, as defined by the Millennium Ecosystem Assessment (MEA, 2005); (2) Industrial Ecology (AYRES e AYRES, 1996), which establishes concepts and principles for this field; (3) the Theory of Fuzzy Sets (ZADEH, 1965) that formally addresses vagueness and associated uncertainties; and (4) AHP (SAATY, 1980) and COPPE-Cosenza Hierarchy Model (2009), which provides insights into metrics and operators for hierarchies. 


\section{Hypotheses/Objectives}

Though studies considering ES in location decisions exist, few are those, which exploit ES as industrial location factors. In this role, ES may be understood as benefits industries obtain from regional ecosystems candidates for location. However, use of ES by industries may cause impacts (costs) of diverse nature and intensity on ES. Of complex valuation in quantitative absolute terms, these benefits and costs may be estimated in qualitative relative terms, respectively, by two ratios: industries' dependence on ES to ES availability in the regions, and by industries' impacts on regional ecosystems to ecosystems' resilience to industries, all according to the perception of experts.

\section{Research Design/Methodology}

Our approach exploits the Theory of Fuzzy Sets (ZADEH, 1965), the formalism of the Analytic Hierarchy Process (AHP) (Saaty, 1981) and the heuristics of COPPE-Cosenza Model. The intent is to get around the complexity of valuations of ES by deterministic methods. We rely on the perception of experts in the environmental, ecosystems and biodiversity field, also versed in production processes of the industries examined and their potential impacts on the ES. We start out by applying the COPPE-Cosenza Model to explicit the level of fulfilment of industries' dependencies on ES by region availability of ES. The linguistic terms utilized as values of the linguistic variables will be modeled as triangular fuzzy numbers to simplify computational manipulation. Dependencies of industries on ES to regions' availability of ES and industries' impact on ecosystems to ecosystems resilience are modeled, respectively, as benefits and costs associated with ecosystem services as locational factors.

\section{Data/Model Analysis}

No real data or model of reality is attempted in this paper.

\section{Limitations}

Limitations envisaged in this approach are differences in perception inherent in experts' diversity in educational background and expertise, experience and participation in assessments of this kind. A search for a perception weight per expert, based on those attributes could be a way to obtain more precision.

\section{Conclusions}

Few studies have attempted to include explicitly ecosystem services as locational factors. Reasons for this are perhaps the complexity involved in absolute quantitative measurement of benefits and costs associated with ES. Our approach seeks to contribute in this direction by presenting a relative measurement, through AHP, which provides a more appropriate metrics for performing the hierarchies and consequently site selection. 
ISAHP Article: A Style Guide for Paper Proposals To Be Submitted to the International Symposium on the Analytic Hierarchy Process 2016, London, U.K.

\section{Key References}

AYRES, R.; AYRES, L. (1996), Industrial Ecology: Towards Closing the Materials Cycle. Edward Elgar, Cheltenham, UK

COSENZA, Carlos Alberto Nunes. 2009. "Hierarchy Models for the Organization of Economic Spaces - Metrics and Operators for Facility Site Selection". Cambridge.

Millennium Ecosystem Assessment, 2005. Ecosystems and Human Well-Being: Synthesis. Island Press, Washington, DC.

ZADEH, L. A. Fuzzy Sets. Information and Control V. 8, pp. 338 - 353, 1965. 